\title{
Early stage chronic kidney disease: a paradigm for diffuse fibrosis and clinical progression
}

\author{
Nicola C Edwards ${ }^{1,2^{*}}$, William E Moody ${ }^{1,2}$, Mengshi Yuan², Shonagh Flanagan ${ }^{2}$, Charles J Ferro ${ }^{2,1}$, \\ John N Townend ${ }^{1,2}$, Richard P Steeds ${ }^{2,1}$ \\ From 17th Annual SCMR Scientific Sessions \\ New Orleans, LA, USA. 16-19 January 2014
}

\section{Background}

Early stage chronic kidney disease (CKD) is an under recognised, highly prevalent cardiovascular $(\mathrm{CV})$ risk factor. Despite a clustering of conventional atherosclerotic risk factors, there is a disproportionate rate of sudden cardiac death, heart failure and stroke rather than myocardial infarction. It is hypothesised that non-atherosclerotic processes, including left ventricular (LV) hypertrophy and fibrosis account for most of the excess CV risk.

\section{Methods}

In total, 30 patients (mean age $57+/-8$ years) with CKD stage 2-4 (mean GFR $58 \pm 22 \mathrm{ml} / \mathrm{min} / 1.73 \mathrm{~m} 2$ ) with no history of cardiovascular disease (mean BP $129 \mathrm{mmHg} \pm$ $13 / 70 \mathrm{mmHg} \pm 11$ ) or diabetes were compared with age and gender matched controls. All subjects underwent cardiac MRI (1.5T Siemens Avanto) for assessment of LV volumes, myocardial deformation (SPAMM tagging) and aortic distensibility. Late gadolinium enhancement (LE) and T1-mapping using a modified look-locker inversion recovery sequence (MOLLI) before and 15 minutes post gadolinium $(0.1 \mathrm{mmol} / \mathrm{Kg})$ for myocardial extracellular volume (ECV) were performed. Global ECV was the average measure from basal and mid short axis slices excluding LGE indicative of infarcted myocardium.

\section{Results}

Global ECV was increased in CKD $(0.30 \pm 0.05$ vs. $0.27 \pm$ $0.03, \mathrm{p}<0.05$ ) with associated reductions in long axis systolic deformation (strain $14.8 \% \pm 2$ vs. $17.1 \% \pm 2$, p < 0.05 ), early relaxation (SR e' $0.50 \pm 0.2$ vs. $0.67 \pm 0.2$, p < $0.05)$ and MAPSE $(13 \mathrm{~mm} \pm 2$ vs. $17 \mathrm{~mm} \pm 3, \mathrm{p}<0.05)$. Aortic distensibility was reduced in CKD (Table 1).

Table $1 \mathrm{CMR}$ parameters of structure and function

\begin{tabular}{ccc}
\hline & CKD $(\mathbf{n}=\mathbf{3 0})$ & Controls $(\mathbf{n}=\mathbf{3 0})$ \\
\hline LVEDVi $(\mathrm{ml} / \mathrm{m} 2)$ & $70(14)$ & $64(13)$ \\
LVESVi $(\mathrm{ml} / \mathrm{m} 2)$ & $21(7)$ & $19(7)$ \\
LV mass index (g/m2) & $63(14)$ & $58(13)$ \\
LVEF (\%) & $71(6)$ & $73(6)$ \\
MAPSE (mm) & $13(2)$ & $17(3)^{*}$ \\
LA volume index (ml/m2) & $45(12)$ & $33(10)^{*}$ \\
Peak longitudinal systolic strain (\%) & $14.8(2.0)$ & $17.1(2.0)^{*}$ \\
Peak longitudinal systolic strain rate (s-1) & $0.71(0.35)$ & $0.91(0.23)$ \\
Early longitudinal diastolic strain rate (s-1) & $0.50(0.17)$ & $0.67(0.24)^{*}$ \\
Aortic distensibility (mmHg-1) & $2.20(1.56)$ & $3.7(1.67)^{*}$ \\
\hline
\end{tabular}

Data $=$ mean $(S D),{ }^{*} p<0.05$

${ }^{1}$ Cardiovascular Medicine, University of Birmingham, Birmingham, UK

Full list of author information is available at the end of the article

(c) 2014 Edwards et al.; licensee BioMed Central Ltd. This is an Open Access article distributed under the terms of the Creative Commons Attribution License (http://creativecommons.org/licenses/by/2.0), which permits unrestricted use, distribution, and reproduction in any medium, provided the original work is properly cited. The Creative Commons Public Domain Dedication waiver (http://creativecommons.org/publicdomain/zero/1.0/) applies to the data made available in this article, unless otherwise stated. 
There were no differences in LV end-diastolic volumes, end-systolic volumes, LV mass index or LV EF (Table 1). Three patients had LGE at the RV insertion points and four patients had diffuse mid-wall LGE in a non-coronary artery territory distribution. NT-proBNP was not increased (median $89 \mathrm{ng} / \mathrm{L}, \mathrm{IQR} 150$ ). ECV did not correlate with conventional $\mathrm{CV}$ risk factors including systolic blood pressure, cholesterol or urinary albumin:creatinine ratio.

\section{Conclusions}

Diffuse LV fibrosis is increased in early CKD with associated reductions in aortic distensibility and abnormal regional systolic and diastolic function. An increase in ECV detected by $\mathrm{T} 1$ mapping might be a key intermediate phenotype and follow-up studies are required to determine if it is predictive of impaired LV systolic function, heart failure events and mortality in CKD.

\section{Funding}

Nil.

\section{Authors' details}

${ }^{1}$ Cardiovascular Medicine, University of Birmingham, Birmingham, UK.

${ }^{2}$ Cardiology, Queen Elizabeth Hospital, Birmingham, UK.

Published: 16 January 2014

doi:10.1186/1532-429X-16-S1-066

Cite this article as: Edwards et al.: Early stage chronic kidney disease: a paradigm for diffuse fibrosis and clinical progression. Journal of

Cardiovascular Magnetic Resonance 2014 16(Suppl 1):O66.
Submit your next manuscript to BioMed Central and take full advantage of:

- Convenient online submission

- Thorough peer review

- No space constraints or color figure charges

- Immediate publication on acceptance

- Inclusion in PubMed, CAS, Scopus and Google Scholar

- Research which is freely available for redistribution

Submit your manuscript at www.biomedcentral.com/submit
C Biomed Central 